\title{
From Willow Wood to Silicone Rubber
}

Due to accidents, birth defects, disease, and the human penchant for war, medical researchers throughout history have searched for ways to replace damaged parts of the human body for both functional and aesthetic reasons. As early as several centuries B.C., crude prostheses were made of natural materials. Today's advances in plastics, ceramics, and metals have made possible artificial components for virtually every mechanical part of the human anatomy, including bones, blood vessels, and heart valves.

Because walking is so important, artificial legs were the first prostheses to be widely accepted. Lower-extremity amputees were willing to accept any sort of prosthesis that would allow them to move about. Wooden legs were used as early as the seventh century B.C., and designs kept improving over the years so that today's versions are generally more sophisticated than other artificial limbs.

Most artificial legs have been made of willow wood because of its durability and flexibility. For a below-knee prosthesis, a wooden socket is fitted to the shape of the stump. A wood and metal foot is attached to the ankle joint to allow some motion of the ankle and toe. Another type of artificial foot, the SACH (for solid ankle, cushioned heel), made of solid metal or wood has layers of rubber on the heel to provide additional cushioning. For stability at the upper end of the prosthesis, metal joints allow the knee to bend more easily, and a heavy leather thigh piece laces tightly to the upper leg. The thigh piece supports some of the wearer's weight so that all the stress is not placed on the stump itself.

In the last few decades, a more modern type of below-knee prosthesis has been made of plastic and fits the stump with total contact. While many of these plastic legs are fitted with the metal knee joints and a thigh piece, others are attached by a strap that passes above the kneecap.

Above-knee leg prostheses are made from two willow sockets. The lower part is similar to the below-knee prosthesis, but the upper part is hollowed out to fit the stump and has braces that extend to the pelvis to support the wearer's weight. The upper and lower parts are fastened together by a mechanical knee joint which, while it does not give the wearer direct control of the leg's bending, still allows reasonably normal walking with practice.

Throughout history, major improvements in the designs of prostheses have occurred after large wars. Surgeon Am-

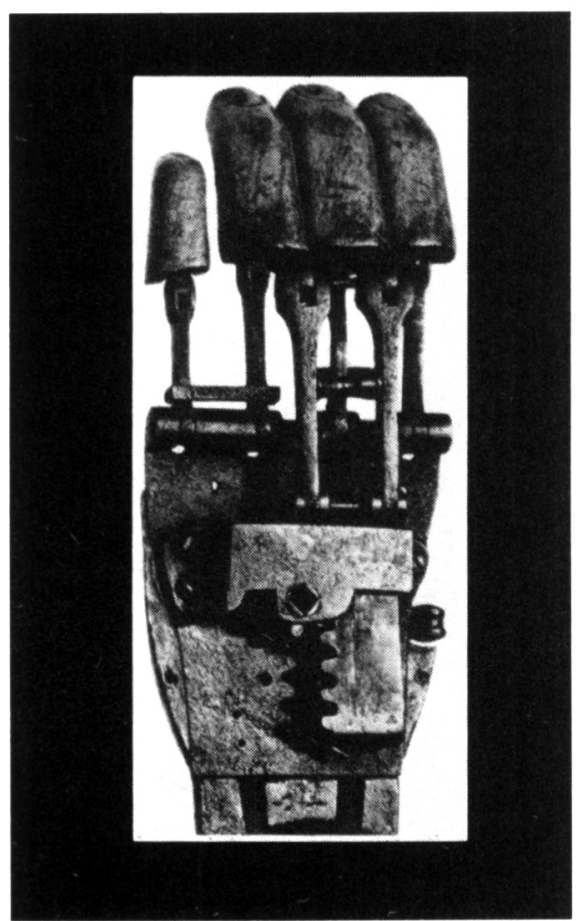

Seventeenth century artificial hand from the Germanisches National Museum,

Nuremburg. Photo courtesy of Dr. Denis C. Lee, University of Michigan Medical Center.

broise Pare is credited with creating the science of prosthetics in France in the 16th century. Paré spent years as a battlefield surgeon and performed many amputations. He devised artificial hands and arms for wounded soldiers.

In the 16th and 17th centuries, other battlefield surgeons created metal hands made either in one piece or with movable parts. After the 18th century, the metal hand gave way to the hook or a singlepiece metal hand covered with leather and attached to the arm stump with a leather or wooden shell. After World War II, the U.S. Army Prosthetic Research Laboratory (APRL) produced the APRL hand, a jointed metal hand covered with a rubber glove colored to match the wearer's skin.

New lightweight materials and better mechanical joints were introduced after World Wars I and II, when arm prostheses began to be made from plastic reinforced with glass fibers. After 1958, numerous birth defects caused by the sedative thalidomide led to voluntary amputations to remove grossly deformed limbs, to be replaced with prostheses. The currently used below-elbow arm is made from a plastic shell and a metal wrist joint containing a hook or hand attachment.

Other body parts have also been replaced. Glass eyes came into use in the 17th century. Danish astronomer Tycho Brahe lost his nose in a duel in 1565 (he and another student engaged in a swordfight to prove who was the better mathematician!) and for the rest of his life he wore a metal cap in the shape of his nose, held in place on his face with a sticky salve. Today, medical sculptors carefully create lifelike noses and ears of silicon rubber.

The replacement and repair of teeth is one of the oldest areas of prosthetic invention. The ancient Etruscans used banded bridges (a span of one or more artificial teeth cemented to adjacent natural teeth); the Phoenicians used wire restorations. Human teeth, animal teeth, or teeth carved from ivory were used as replacements. Entire upper or lower dentures were carved from solid pieces of wood or ivory.

In the latter part of the 18th century, teeth fashioned from porcelain were introduced. Plastic teeth came into use in the current century. The color and texture of teeth vary greatly from person to person, but new porcelain and plastic materials have been developed to the point where crowns, bridges, and partial or complete dentures are nearly indistinguishable from natural teeth. Chrome alloys and gold alloys have been developed with material properties specific to uses as clasps, bars, and bases for prosthodontic attachments.

Stainless steel, chrome cobalt, and silver have been used for years as pins and as plates and artificial joints to repair faulty hip joints or damage to the skull and jaw.

Replacing damaged or faulty soft tissue, such as cartilage and organ tissue, proved an insurmountable problem until the introduction of medical-grade silicones. Hydrocephalus shunts, which drain excess cranial fluid from the brain, are made from Silastic silicone rubber and have been implanted in over 200,000 patients. Arteries of Dacron and Teflon have been used in many other people. Silastic silicone rubber and medical-grade silicone fluid are being used to reconstruct soft tissue destroyed by accidents, cancer, or birth defects. Other new biomaterials are being fabricated for specialized replacements in the human body, including artificial skin, bladders, corneas, bile ducts, urethras and ureters, and tracheas.

Kevin J. Anderson 


\section{The first series designed to meet all the demands of scientists and engineers working with high-performance materials...}

\section{Materials Science and Technology in 18 volumes}

Editors-in-Chief:

R. W. Cahn,

University of

Cambridge, U.K.

P. Haasen,

University of Göttingen,

Germany

E. J. Kramer,

Cornell University, U.S.A.

$\bullet \bullet \bullet \bullet$

The Materials Science and Technology Series is designed to meet the needs of scientists and engineers who populate the discipline of materials science -- experts in physics, metallurgy, chemistry, ceramic and polymer science

and technology, chemical engineering, energy technology, electronics and electrical engineering, and medical physics.

Combining the efforts of more than 200 prominent international scientists, the work spans prodigious amounts of material within a topical structure that facilitates fundamental and practical research, frequent reference and systematic study by materials science professionals in a variety of disciplines.

Each volume details a particular subdiscipline of materials science and technology, contains between 10 and 20 chapters in about 500 pages, features extensive cross-referencing, thorough bibliographies and its own subject index. Because of their

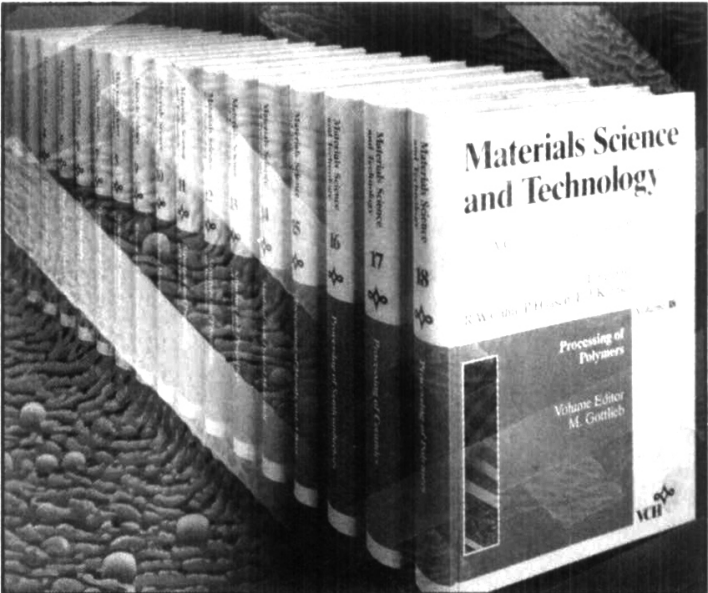

ed. W. Schröter, University of Göttingen, Germany, 0-89573-692-6, November, 1991 -Volume5, Phase Iranstormations in Moterials, ed. P. Haasen, University of Göttingen, Germany, 0-89573-693-4, January, 1991

-Volume 7, Constilution and Proportles of Steels

ed. F. B. Pickering, Sheffield City Polytechnic, U.K.,

0-89573-695-0, November, 1991

"Volume 9, Glasses and Amorphous Materials ed. J. Zarzycki

University of Montpellier, France,

topical nature, individual volumes are also suitable as specialized graduate texts. A Cumulative Index will be published upon completion of the series.

In the Materials Science and Technology Series, the specialist will find an up-to-date presentation of his own and neighboring disciplines, while the generalist will gain considerableinsight and knowledge in new territory. The series is a must for all materials science and engineering library collections, laboratories, industry and departmental reference shelves, and research institutes.

The complete list - scheduled for completion by 1994 :

Volume 3, Electronic and Magnetic Properties of Metals and Ceramics ed. K. H.J. Buschow

Philips Research Laboratories, Eindhoven, The Netherlands

-3A: 0-89573-691-8, October, 1991

- Volume 4, Electronic Structure and Properties of Semiconductors
0-89573-697-7, October, 1991

-Volume 14, Medical and Dental Materials, ed. D.F. Williams, University of Liverpool, U.K.,

0-89573-801-5, January, 1992

- Volume 15, Processing of Metals and Alloys, ed. R. W. Cahn, University of Cambridge, U.K.,

0-89573-802-3, August, 1991

- Volume 17, Processing of

Ceramics, ed. R. J. Brook, Max-Planck-

Institute für Metallforschung,

Stuttgart, Germany, 0-89573-804-X,

December, 1991

Series ISBN 1-56081-551-5

Price Per Volume $\$ 325.00$

Subscription $\mathbf{\$ 2 7 0 . 0 0}$

- Already Published " Coming Soon

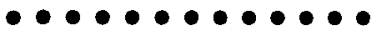

VCH Publishers, Inc. 220 East 23rd Street. Suite 909

New York, NY 10010 or

Call Our Toll-Free Number:

$\bullet \bullet \bullet \bullet \bullet \bullet$ 1-800/367-8249

\section{For a brochure with complete contents of each volume, please use the reader service card}

